A UTHORS ARSTRACT OF THIS PAPER ISSUED

BY THE GIBLIOGRAPUIC AERVICE, OCTOBER 8

\title{
THE EARLY APPEARANCE OF THE ANLAGEN OF THE PARS TUBERALIS IN THE HYPOPHYSIS OF THE CHICK
}

WAYNE J. ATWELL AND IDA SITLER

Department of Analomy, Medical School of the University of Michigan

FIVE FIGURES

It is now well recognized that the epithelial portion of the hypophysis consists of three distinct parts. The pars anterior propria is the principal epithelial lobe and constitutes the main bulk of the gland, the pars intermedia is a thin layer, epithelial in nature, which becomes intimately associated with the neural lobe. The most recently recognized epithelial lobe is the pars tuberalis--so named by Tilney ('13) on account of its close relation to the tuber cinereum. It extends forward from the junction of the pars intermedia and the pars anterior propria, surrounding the infundibular stalk and spreading out for some distance under the brain floor.

The pars tuberalis has been sometimes confused with the pars intermedia-Lothringer ('86) and Herring ('08)--but recent studies have shown conclusively that these two parts are different both in adult structure and in developmental history. Tilney, in summarizing the development of the pars tuberalis in the chick and the cat, states:

In addition to the histological differences between these two parts, the ontogenesis of the organ as observed in the cat and the fowl still further emphasizes the fact that the pars tuberalis and the pars infundibularis (pars intermedia) are morphologically distinct elements. The pars infundibularis makes its appearance immediately after the anlage of the buccal portion of the hypophysis is formed. The pars tuberalis arises as a relatively late strueture. It has its origin in two secondary diverticula or sprouts from the body of the pituitary sac. These sprouts, the tuberal processes, ultimately fuse with each other across the median line, displace the body of the pituitary sac ventrad and thus secondarily assume their juxta-neural position. 
One of us-Atwell ('18)-in a recent study of the development of the hypophysis in the rabbit has obtained somewhat different results. While agreeing with Tilney as to the distinctness of the pars tuberalis and the pars intermedia, and also confirming the statement that the pars tuberalis is late in acquiring its adult relationship with the tuber cinereum, it has been found that in the rabbit the anlagen of the pars tuberalis may be discerned very early. They were found to precede the definite pars intermedia by a considerable period of time.

It was with the hope of throwing some light upon this point that the present study was undertaken. Accordingly we have been led to construct a number of wax-plate models of the epithelial hypophysis from chick embryos, beginning with stages in which the tuberal processes might be recognized easily and then proceeding to successively younger embryos in an effort to determine the earliest appearance of the anlagen.

The literature relating to the lateral lobes and the pars tuberalis in the hypophysis of the chick is not extensive.

Rossi ('96) speaks of a median and two lateral parts in the early hypophysis of the chick embryo. According to Rossi the lateral lobes are secondary structures.

Economo ('99) observed a pair of 'Seitensprossen' in the hypophysis of the dove and of the domestic fowl. In dove embryos the sprouts appear between the fourth and seventh days of incubation. No definite statement is made concerning the first appearance of the sprouts in the chick.

Tilney ('13) first observed the 'tuberal processes' in a chick embryo of 5 days and 20 hours of incubation. From this stage the processes were traced to the formation of the pars tuberalis of the adult fowl. Although a reconstruction was prepared from an embryo of four days of incubation the tuberal processes were not seen in this stage. Embryos younger than four days were not studied.

Woerdeman ('14) notes that the lateral lobes are forming in a chick embryo of about 72 hours of development. The thickened epithelium which lies in front of Rathke's pocket is constricted off from the mouth cavity by two lateral folds. Woerdeman con- 
siders that the lateral lobes so formed arise independently of Rathke's pocket.

Bruni ('15) observes the presence of two 'lobi laterali' in the chick at 82 hours of incubation. He also figures and describes the lateral lobes in older embryos but does not trace them into the formation of the pars tuberalis.

\section{OBSERVATIONS}

We have prepared wax-plate reconstructions of the epithelial portion of the hypophysis from chick embryos of $48,59,67,72,96$, 120 and 144 hours of incubation. A relatively high magnification was chosen for the construction of the models in order that all details of structure might be shown as accurately as possible. For all younger stages, including the 72 hour embryo, the magnification was 300 diameters. For the older embryos the magnification was reduced to 200 diameters.

Chick embryo, 48 hours of incubation (21-2 pairs of primitive segments). Fig. 1. The hypophyseal pouch is well formed but opens widely into the mouth invagination. There is no indication of the lateral lobes. The anterior end of the fore-gut, which will later form Seessel's pouch, extends farther cranially than does the hypophyseal pouch. At this time the oral membrane is intact.

Chick embryo, 59 hours of incubation (30 pairs of segments). The hypophyseal pouch (Rathke's pocket) has deepened and now exhibits two lateral enlargements near its attachment to the oral epithelium. As later models show, these are the anlagen of the lateral lobes from which the tuberal processes develop. As may be seen from figure 2, Rathke's pocket is slightly constricted just above the lateral lobes. The lateral lobes have the form of blunt ridges which protrude laterally and also somewhat nasally. Their long axes lie parallel with the long axis of the entire hypophyseal pouch. This embryo shows one small perforation in the oral membrane.

Chick embryo, 67 hours of incubation. The lateral lobes are more prominent at this stage due to the fact that the hypophyseal pouch is beginning to be constricted somewhat from the 
WAYNE J. ATWELL AND IDA SITLER
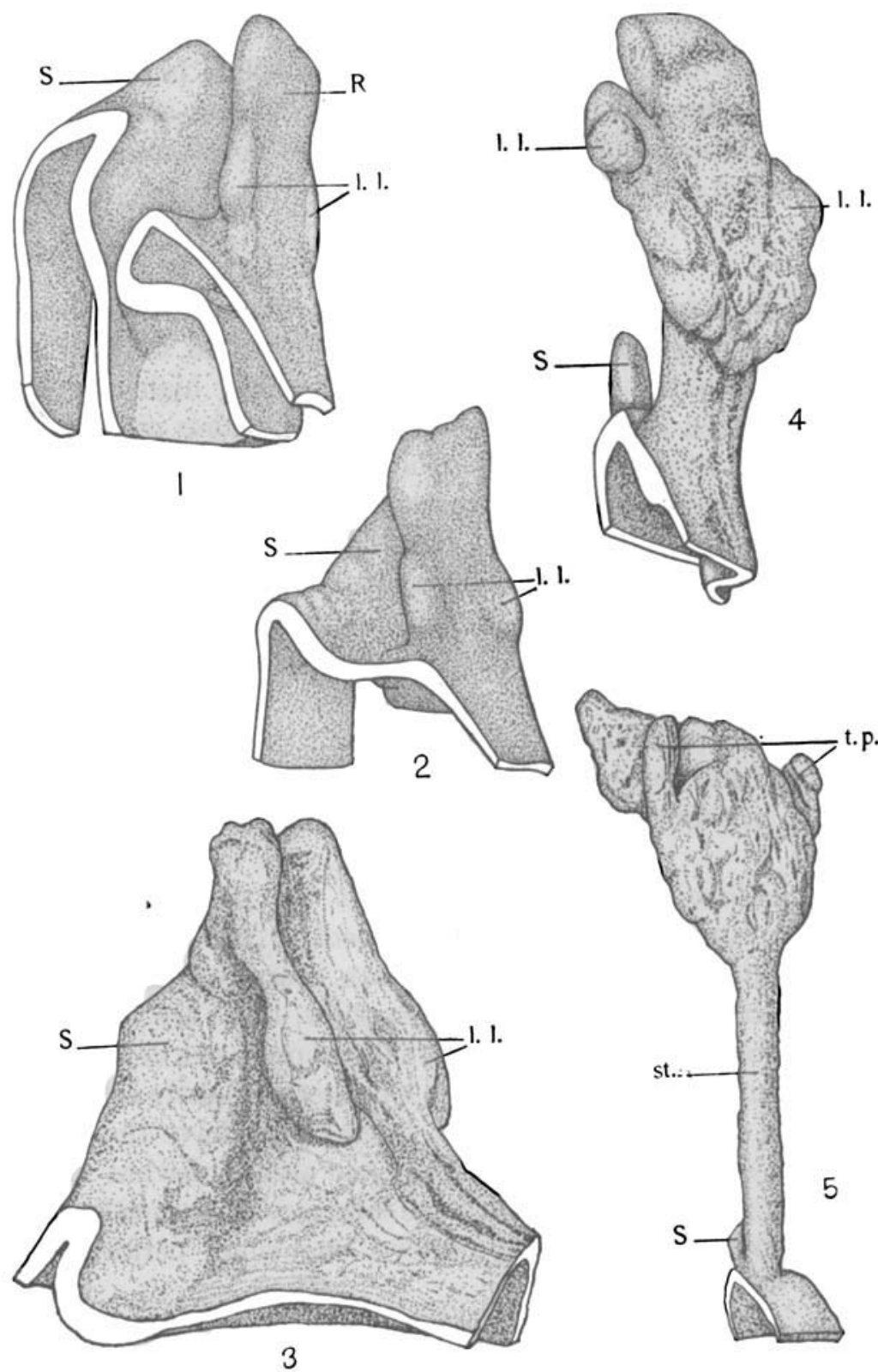
oral cavity. The constriction of Rathke's pocket dorsal to the lateral lobes is also more distinct than previously. Each lateral lobe contains a lumen communicating with the cavity of the main hypophyseal sac. Seessel's pouch is in contact with the dorsal wall of Rathke's pocket for a considerable area. This is the ecto-entodermal fusion which has been recorded by numerous observers.

Chick embryo, 72 hours of incubation, figure 3. The hypophysis anlage is closely applied to the brain wall, causing the nasal surface of the pouch to be sharply concave. The lateral lobes are more prominent than in the preceding stage. The lumen of the pouch extends well into each lateral lobe. One striking feature is the extensive degree of communication between the cavity of Seessel's pouch and the hypophyseal sac. The two open into each other almost to the summit of the ecto-entodermal fusion. This causes the opening of the hypophyseal sac into the oro-pharynx to be relatively larger than in previous stages. From an examination of embryos of this age alone the impression might be gained that the lateral lobes are being added to Rathke's pocket. A critical comparison of this and younger stages, however, indiates strongly that the lateral lobes of the chick do not arise independently of Rathke's pouch, but that they are formed from it. In this we support the observations of Rossi.

Chick embryo, 96 hours of incubation. The principal feature of interest in this stage is the beginning recession of Seessel's pouch and its separation from the hypophyseal sac. The lateral lobes are more sharply marked off from the superior part of the hypophysis, but otherwise this stage does not exhibit any striking differences from the preceding.

All figures represent wax-plate reconstructions of the epithelial hypophysis as viewed from in front and from the left side. $S$, Seessel's pouch, $R$, Rathke's pouch, l.l., lateral lobes, t.p., tuberal processes, st., hypophyseal stalk.

Fig. 1. Hypophysis region from chick embryo of 21-2 pairs of primitive segments (end of second day of incubation). $\times 100$.

Fig. 2. Hypophysis from chick embryo of 30 pairs of primitive segments (59 hours of incubation). $\times 100$.

Fig. 3. Hypophysis from chick embryo of 72 hours of incubation. $\times 100$.

Fig. 4. Hypophysis from chick embryo, 5 days (120 hours) of incubation. $\times 75$.

Fig. 5. Hypophysis from chick embryo, 6 days (144 hours) of incubation. $\times 75$. 
Chick embryo, 5 days (120 hours) of incubation. By this time a definite hypophyseal stalk has been formed. It is hollow and affords a communication between the lumen of the hypophysis and the oral cavity. The lateral lobes have increased in size so that the transverse diameter of the gland, measured between the lateral extremities of the two lobes, is almost twice thetransverse diameter of the superior part of Rathke's pocket. The lateral lobes are united by a prominent ridge around the inferior and nasal end of the hypophysis. This solid median protuberance doubtless corresponds to a vestigial 'Vorraum' or 'corpus lobuli bifurcati' of other vertebrates as described by Woerdeman. The lateral lobes are beginning to be solid, also. At this stage they sometimes contain lumina, which, however, no longer communicate clearly with the main hypophyseal cavity.

Seessel's pouch is represented by a solid bud of epithelial cells just dorsal to the hypophyseal stalk (S, fig. 4). Curiously enough Economo labels this bud the remains of Rathke's pocket.

Chick embryo, 6 days (144 hours) of incubation. The hypophyseal stalk is much elongated and has become solid. Near its connection with the oral epithelium may be seen the bud-like remains of Seessel's pouch. The superior, or distal, half of the hypophysisis is bent dorsally and forms an angle of about ninety degrees with the inferior or proximal half of the gland. The constriction near the middle of the gland is pronounced. Distinct 'tuberal processes' have formed from the lateral lobes. Instead of projecting so much laterally, they are now directed toward the brain wall. The tuberal processes are not located at the extreme nasal end of the gland but are seen to protrude from about the middle of the inferior half (fig. 5).

\section{SUMMARY}

The lateral lobes, from which the tuberal processes arise, may be distinguished in a chick embryo having 30 pairs of primitive segments. From a careful study of stages preceding and following the rupture of the oral membrane it is evident that the lateral lobes are not formed independently of Rathke's pocket 
and later added to it, but are rather formed secondarily from the nasal wall of the early hypophyseal anlage.

The lateral lobes, in all forms studied, appear early in development. This would indicate that they and their derivative in higher vertebrates, the pars tuberalis, are of fundamental phylogenetic importance. Thus great interest is attached to the broad homologies drawn by Woerdeman ('14).

\section{LITERATURE}

ATWELL, WAYNE J. 1918 The development of the hypophysis cerebri of the rabbit (Lepus cuniculus L.). Amer. Jour. Anat., vol. 24, p. 271.

Bruni, A. C. 1915 Sullo sviluppo del lobo ghiandolare dell' ipofisi negli Amnioti. Internat. Monatschr. f. Anat. u. Physiol., Bd. 31, S. 129.

Economo, C. J. 1899 Zur Entwicklung der Vogelhypophyse. Sitzber. d. kais. Akad. d. Wiss., math.-naturw. Classe, Bd. 108, Abth. 3, S. 381.

Herring, P. T. 1908 The histological appearances of the mammalian pituitary body. Quar. Jour. Ex. Physiol., vol. 1, p. 121.

Lothringer, S. 1886 Untersuchungen an der hypophyse einiger Säugethiere und des Menschen. Arch. f. mikr. Anat., Bd. 28, S. 257.

Rossi, U. 1896 Sui lobi laterale della Ipsofisi. Monit. Zool. ital., 7, p. 240.

ThLNEY, Fredericr 1913 An analysis of the juxtra-neural epithelial portion of the hypophysis cerebri, with an embryological and histological account of an hitherto undescribed part of the organ. Internat. Monatschr. f. Anat. u. Physiol., Bd. 30, S. 258.

Woerdeman, Martin W. 1914 Vergleichende Ontogenie der Hypophyzis. Arch. f. mikr. Anat., Bd. 86, S. 198. 